\title{
Estimation of thermal diffusivity of soils in Antarctica using temperature time series data
}

\author{
${ }^{1}$ The Research Institute for Earth Resources, Kangwon National University, Chuncheon 24341, Republic of Korea. \\ ${ }^{2}$ Department of Geology, Kangwon National University, Chuncheon 24341, Republic of Korea; *Corresponding author, E-mail: hydrolee@kangwon.ac.kr \\ ${ }^{3}$ Critical Zone Frontier Research Laboratory (CFRL), Kangwon National University, Chuncheon 24341, Republic of Korea. \\ ${ }^{4}$ Korea Polar Research Institute, Incheon 21990, Republic of Korea
}

(Received: August 9, 2019; Revised accepted: August 22, 2019)

https://doi.org/10.18814/epiiugs/2019/019020

Thermal diffusivity is a physical quantity that represents the thermal properties of soil. Amid the climate change known as global warming faced by humanity, Antarctica is one of the regions most affected by such changes. Therefore, in order to counter the effects of climate change, the thermal diffusivity of Antarctic regions is estimated in advance. In this study, the thermal diffusivities of four different locations near the King Sejong Station were estimated using temperature data measured in Antarctic soils, and temperature time series data were simulated using the finite element method. The thermal dynamic of active layer is analyzed in the soil temperature with high temporal resolution and high accuracy. In active layer of Antarctica area, calculation of thermal diffusivity is closely correlated with the freezing of excess water. From the warm and cold period, the pattern of heat production was calculated at the depth of $20 \mathrm{~cm}$. The results showed that the thermal diffusivities of SJL1, SJL2 and SJL4 were $14 \times 10^{-7}, 12 \times$ $10^{-7}$, and $11 \times 10^{-7} \mathrm{~m}^{2} / \mathrm{s}$ with root-mean-square (RMS) errors of $0.19953,0.21182$, and $0.32168^{\circ} \mathrm{C}$, respectively. The shallow geothermal gradient data of study points showed the change from cooling and heating processes except SJL3 point. The calculated thermal diffusivities of the study points range from $11 \sim 14 \times 10^{-7} \mathrm{~m}^{2} / \mathrm{s}$, which is consistent with previous reports.

\section{Introduction}

Polar regions are one of the regions most affected by climate change, a phenomenon caused by global warming that humanity faces today. Polar regions also have a strong influence on the global climate. Therefore, a number of researchers are conducting studies on polar regions to understand their role in climate (Roth and Boike, 2001; Pringle et al., 2003; Pringle et al., 2007; Wu and Zhang, 2010; Weismüller et al., 2011; Lee et al., 2016; Kim et al., 2018). In doing so, quantitative consideration of the thermal and physical properties of the active lay- ers of permafrost in polar regions is essential in understanding the meteorological characteristics of permafrost regions as well as predicting the interaction between the atmosphere and permafrost surface (Pringle et al., 2003; Boike et al., 2008; Ikard et al., 2009; Jeon et al., 2016).

Permafrost refers to ground made up of earth rocks and sediments that maintains a temperature of $0^{\circ} \mathrm{C}$ or below for two years or more. Permafrost covers approximately one-fourth of exposed land in the Northern Hemisphere and plays a key role in the global thermal system (Bockheim et al., 2007; Vieira et al., 2010; Bockheim et al., 2013). The thermal characteristics of soil depend on its porosity and water content as well as the density, specific heat, and thermal conductivity of its particles.

In polar regions, temperature changes on the surface and active layer are sensitive to atmospheric temperature, and the area of the active layer is changing owing to global warming (Yoshikawa and Hinzman, 2003; Marchenko et al., 2008; Koven et al., 2013). Heat transfer is extremely complex, especially in these active layers of permafrost, and depends on different mechanisms such as heat generation from conduction and phase changes as well as movements of water and vapor (Boike et al., 1998; Pradhan et al., 2019). Thermal conduction refers to the transfer of heat from areas of high temperature to tangential areas of low temperature without physical mass transfer; it is widely known as the primary method of heat transfer in soil (Han et al., 2006; Ebel et al., 2019).

Nonconductive heat transfer mediums, particularly those associated with groundwater convection, are available with suitable temperature gradient in a liquid or vapor state. Thermal diffusivity is a physical quantity that represents the thermal properties of soil. Methods for estimating thermal diffusivity of soil exist in various literatures (Romanovsky et al., 2003; Wu and Zhang, 2010; Wang et al., 2019). In the case of rocks, thermal diffusivity can be measured by experimenting with collected samples (Nabelek et al., 2012). However, as it is impossible to collect undisturbed soil samples, the thermal diffusivity of soil is usually determined by analyzing temperature observation data (Han et al., 2005; Koo and Song, 2008; Kim et al., 2018).

A number of publications have estimated the thermal diffusivity of soil using equations such as amplitude equations, phase equations, algebraic equations and finite-difference equations derived from the 
analytical or numerical solution of one-dimensional thermal conductivity equations (Hinkel, 1997; Pringle et al., 2003; Cui et al., 2012). These methods of estimating thermal diffusivity that use analytical or numerical solutions of the heat conductivity equation generally neglect nonconductive heat transfer processes such as fluid flow in air gaps, freezing and melting of water, evaporation, etc. Moreover, thermal diffusivity calculated using such methods may be over- or underestimated as the coefficient itself is affected by the method used to obtain it. This is especially true for methods using amplitude equations and algebraic equations, whose results are affected by nonconductive heat transfer from water flowing within the soil.

Similarly, methods using finite-difference equations exhibit large sensitivity to observational error of the truncation error, making them less reliable in applying measured data (Koo et al., 2003). Therefore, in this study, thermal diffusivity was estimated with temperature time series data simulated using the finite element method, and depth-specific temperature data collected from four different locations near the King Sejong Station.

\section{Methods and Materials}

\section{Geology of Study Area}

The area of study is the region surrounding the King Sejong Station located in the Barton peninsula of King George Island of the South Shetland Islands, northwest of the Antarctic peninsula. The region is populated with bases of diverse nationalities that study the Antarctic's ecology and environment. King George Island is the largest island among the South Shetland Islands, with length, width and area of $72 \mathrm{~km}, 27 \mathrm{~km}$ and 1,338 km², respectively (Chang, 2003). It is one of many volcanic islands (Smellie et al., 1984) associated with the subduction of oceanic plates that occurred between the late Mesozoic and early Cenozoic.

The Barton peninsula and Weaver peninsula located southwest of the island mainly consist of volcanic granules in their lower sections and calk-alkaline volcanic/plutonic rocks in their upper sections. The Barton peninsula is an elevated glacial landform (Yoo et al., 2001). The fact that Maxwell Bay and Marian Cove are fjords, and that the surface of the Barton Peninsula is rather flat, proves that Barton Peninsula is a glacial landform. Likewise, the remains of rounded pebbles found in the higher areas of the peninsula prove that it is an elevated landform as well (John and Sugden, 1971).

The surface of the Barton Peninsula mainly consists of bedrock, moraine, weathered volcanic materials, structural soil and back beach (López-Martinez et al., 2002). Rocks pressed and packed by drift ice form patterned intertidal flats and patterned beaches at the intertidal zones near the King Sejong Station. The station is located near the shores at the northwest end of the Barton Peninsula, southwest of King George Island. The base of the Barton peninsula on which the station is located is a layer of sedimentary volcanic rock known as the Sejong layer covered by alkaline with unconformity.

At the bottom of the Barton-Weaver Peninsula's geological stratum is the Sejong layer, which mainly consists of lapilli and lapilli tuff. It also contains various types of silt and volcanic rock fragments. The layer is a pyroclastic layer with total thickness of approximately
$100 \mathrm{~m}$. According to the sedimentary rocks and sedimentary structure, the Sejong layer has five major layers: first, structureless substrate conglomerate; second, structureless pebbly conglomerate; third, stratified pebbly conglomerate; fourth, lamellar sandstone; and finally, lapilli tuff.

Plant fossils found within the silt and fine sandstone of the Sejong layer are leaves that belonged to ferns and broadleaf trees that inhabited the region from the late Paleocene to Eocene. The presence of such fossils indicates a tropical-subtropical climate (Chun and Chang, 1991; Chang et al., 2003; Lee et al., 2019). Rock fragments mainly consist of andesite, basaltic andesite and pumice, and a large number of rhyolitic shards are formed in some layers (Fig. 1).

\section{Acquisitions of Soil Temperature Data}

Thermal temperature loggers (iButton, Dallas Semiconductor, USA) were installed in four different locations at depths of 10, 20 and $30 \mathrm{~cm}$ : two locations (SJL1 and SJL2) in the east and two locations (SJL3 and SJL4) in the west of the living hall of the King Sejong Station (Fig. 2) The iButton loggers were installed to measure temperature over time, and have an accuracy of $0.5^{\circ} \mathrm{C}$ with a resolution of $0.0625^{\circ} \mathrm{C}$. Soil temperature measurements were taken every $4 \mathrm{~h}$ from December 23, 2010 to November 28, 2011. According to Lee et al. (2013), the effects of time delay and attenuation on the temperature measurements of an iButton placed in soil in a glass bottle are not significant. Using the methodology proposed by Lee et al. (2013), depthspecific soil temperature time series data were obtained at four different locations (SJL1, SJL2, SJL3, and SJL4) near the Antarctic King Sejong Station (Fig. 2).

\section{Theoretical Background}

The law of conservation of energy can be expressed as the following equation.

$$
\frac{\partial}{\partial t}[c T]+\nabla \cdot \vec{q}=A
$$

where $c=$ heat capacity

$$
\begin{aligned}
& T=\text { temperature }\left({ }^{\circ} \mathrm{C}\right) \\
& \vec{q}=\text { heat flux } \\
& A=\text { heat production rate }
\end{aligned}
$$

Heat flow by Fourier's law is according to the following.

$$
\vec{q}=-k \nabla T
$$

Thus, the heat transfer equation can be derived from equations (1) and (2).

$$
\nabla^{2} T+\frac{A}{k}=\frac{1}{\alpha} \frac{\partial T}{\partial t}
$$

where $k=$ thermal conductivity

$$
\alpha=\text { thermal diffusivity }
$$

When equation (3) is given as a function in which the initial temperature is 0 , and surface temperature is $T(0, t)$ in a semi-infinite medium where the production and extinction of soil heat do not occur, its solution is given as the convolution of the surface temperature function 


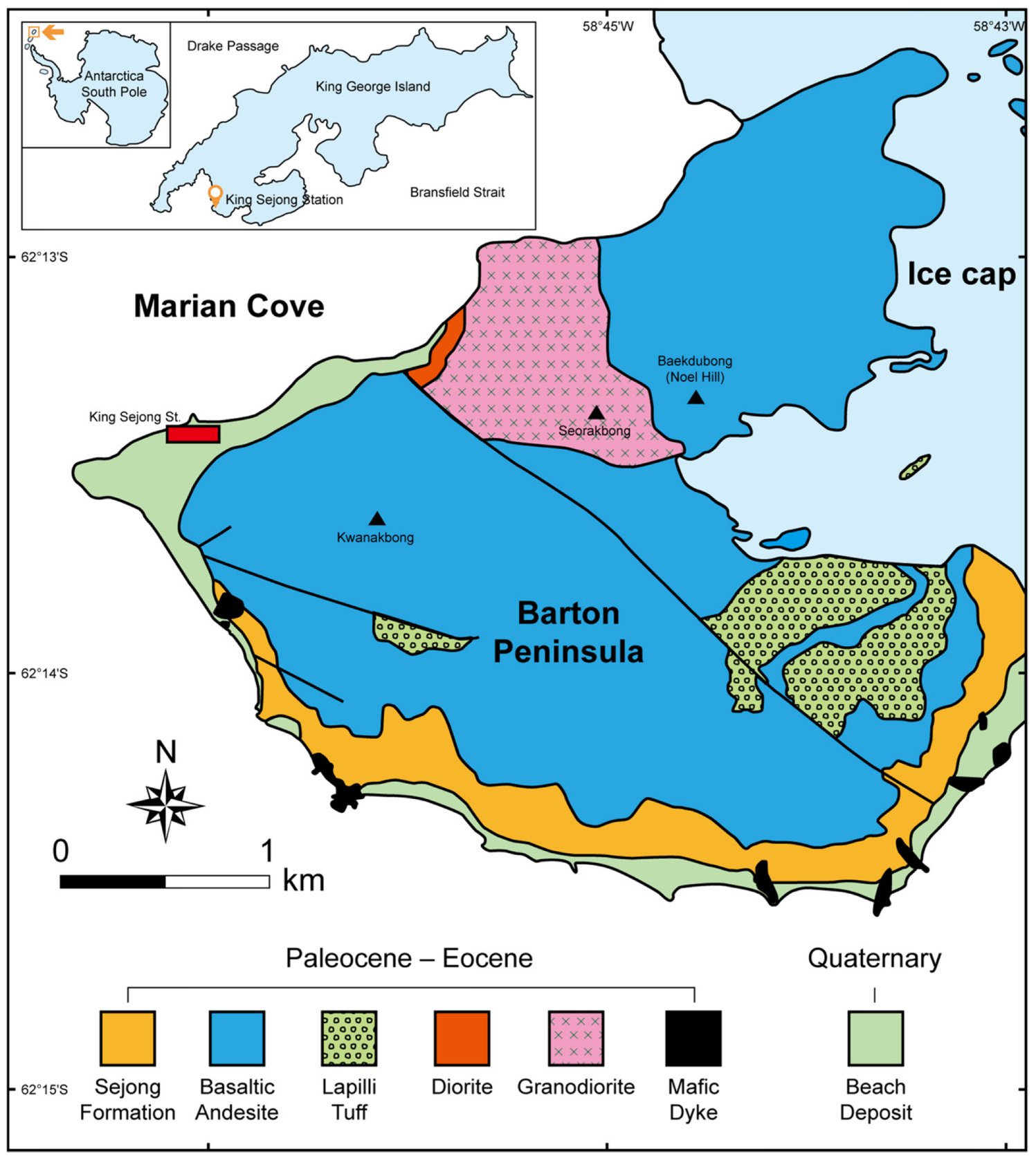

Figure 1. Geological map of Barton-Weaver Peninsulas, King George Island, Antarctica (modified from Lee et al., 2019).

and the transfer function $\left(f_{\tau}\right)$ (Carslaw and Jaeger, 1986).

$$
T(z, t)=\int_{0}^{t} T(0, \tau) f_{T}(t-\tau, z) d \tau
$$

Here, the transfer function is as follows.

$$
f_{1}(t, z)=\frac{z}{2\left[\pi \alpha t^{3}\right]} \exp \left(-\frac{z^{2}}{4 \alpha t}\right)
$$

Accordingly, the change of temperature in the subsurface, which occurs only by heat conduction in a uniform medium without production and extinction of soil heat, can be calculated using equations (4) and (5). In addition, since the soil temperature measurement is performed discretely according to depth, equation (2), as a finite difference method approximation, can calculate heat flow according to depth as follows.

$$
q=-k \frac{T\left(z_{i+1}, t\right)-T\left(z_{i}, t\right)}{z_{i+1}-z_{i}}
$$

Here, the heat production rate at $\left[z_{i}, z_{i+1}\right] \times\left[t^{j}, t^{j+1}\right]$, the small section of depth and time, can be obtained as follows by Roth and Boike's equation (Roth and Boike, 2001; Han et al., 2006).

$$
\begin{aligned}
& A=\frac{1}{\left[t^{j+1}-t^{j}\right]\left[z_{i+1}-z_{i}\right]} \int_{t^{j}}^{t^{j+1}} \int_{z_{i}}^{z_{i+1}} A(z, t) d z d t=\frac{1}{\left[t^{j+1}-t^{j}\right]\left[z_{i+1}-z_{i}\right]} \\
& c\left[\int_{z_{i}}^{z_{i+1}}\left\{T\left(z, t^{j+1}\right)-T\left(z, t^{j}\right)\right\} d z-\alpha \int_{t^{j}}^{j^{j+1}}\left\{T^{\prime}\left(z_{i+1}, t\right)-T^{\prime}\left(z_{i}, t\right)\right\} d t\right]
\end{aligned}
$$

$T^{\prime}=$ differential difference according to the depth of soil heat 


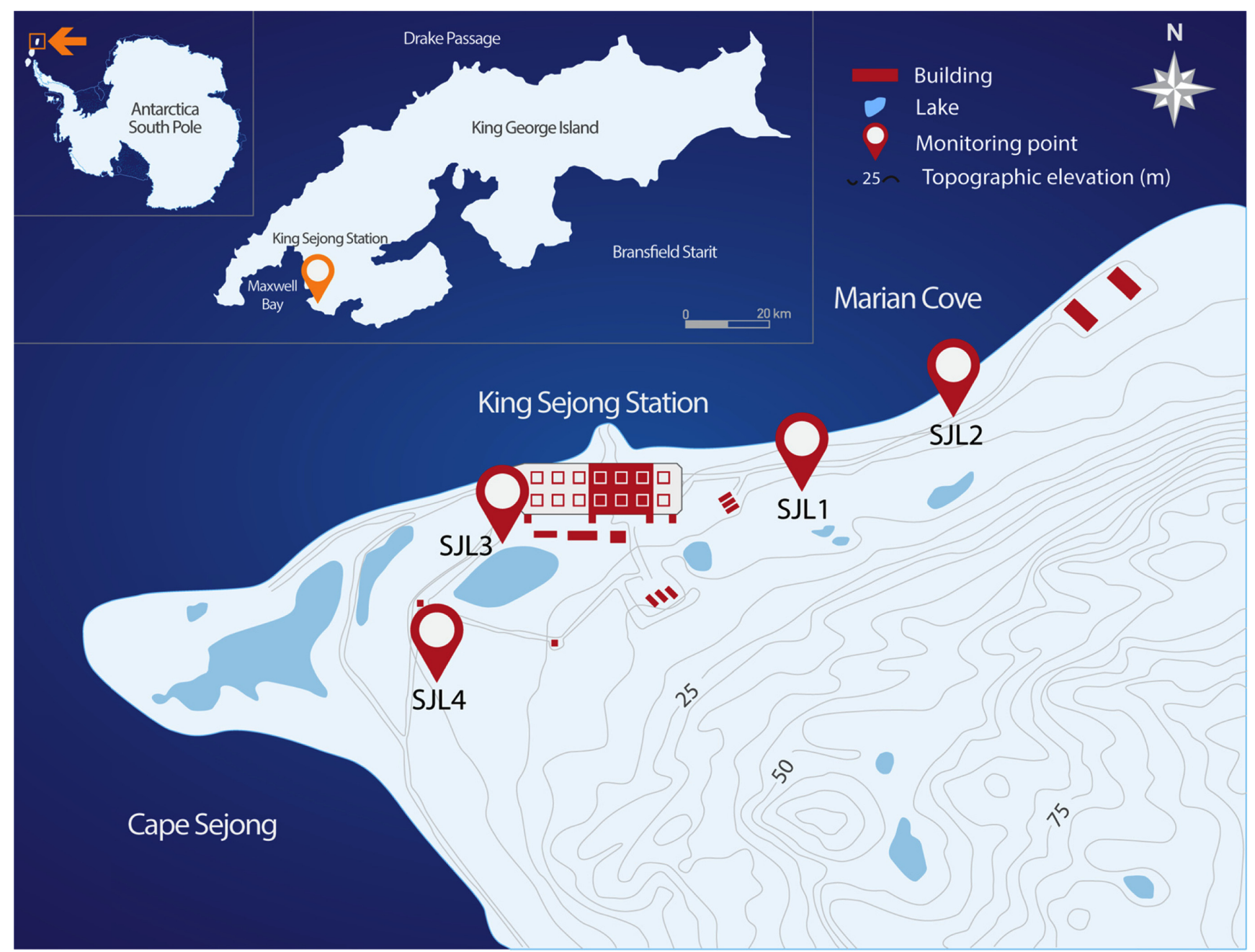

Figure 2. Monitoring locations of surface temperature at the King Sejong Station in the Antarctica (modified from Kim et al., 2018).

To compensate for the fundamental problems with the aforementioned methodologies such as amplitude equation, the phase equation, the logarithmic equation and the finite difference equation the thermal diffusivity was estimated using the FEM in this study (Kim et al., 2018). The reasons of the widely used of the FEM are well known. That are local character of approximations, ability to deal with complex geometric domains, existence of large set of approximation schemes adapted to various problems but embedded in a unified formulation. Furthermore, FEM procedures are generally used in structural problems and in non-structural problems, such as fluid flow and heat transfer problems (Bathe, 1996; Kim et al., 2018).

\section{Results and Discussion}

The assumption of thermal diffusivity of active layer in Antarctic soils was scored by calculating the root-mean-squared (RMS) error between the measured target and calculated response signals. The RMS error was used because it is a widely recommended measure of tracking accuracy (Kim et al., 2018). Fig. 3 shows the RMS errors between the temperature measured points. The time range between $5,500 \sim 6,000 \mathrm{~h}$ was adopted for RMS error calculation for SJL1 and SJL4 points. However, the locations of SJL2 andSJL3 were unsuc-

Table 1. Time range for RMS error calculation and calculated thermal diffusivity

\begin{tabular}{|c|c|c|c|}
\hline Location & Time range for RMSE cal. & $\alpha_{\text {opt }}\left(\times 10^{-7} \mathrm{~m}^{2} / \mathrm{s}\right)$ & RMSE $\left({ }^{\circ} \mathrm{C}\right)$ \\
\hline SJL1 & $5,500-6,000$ & 14 & 0.19953 \\
\hline SJL2 & $5,500-6,000$ & 4 & 0.18515 \\
\hline SJL2 & $3,500-4,000$ & 12 & 0.21182 \\
\hline SJL3 & $5,500-6,000$ & 9 & 0.70905 \\
\hline SJL4 & $5,500-6,000$ & 11 & 0.32168 \\
\hline
\end{tabular}



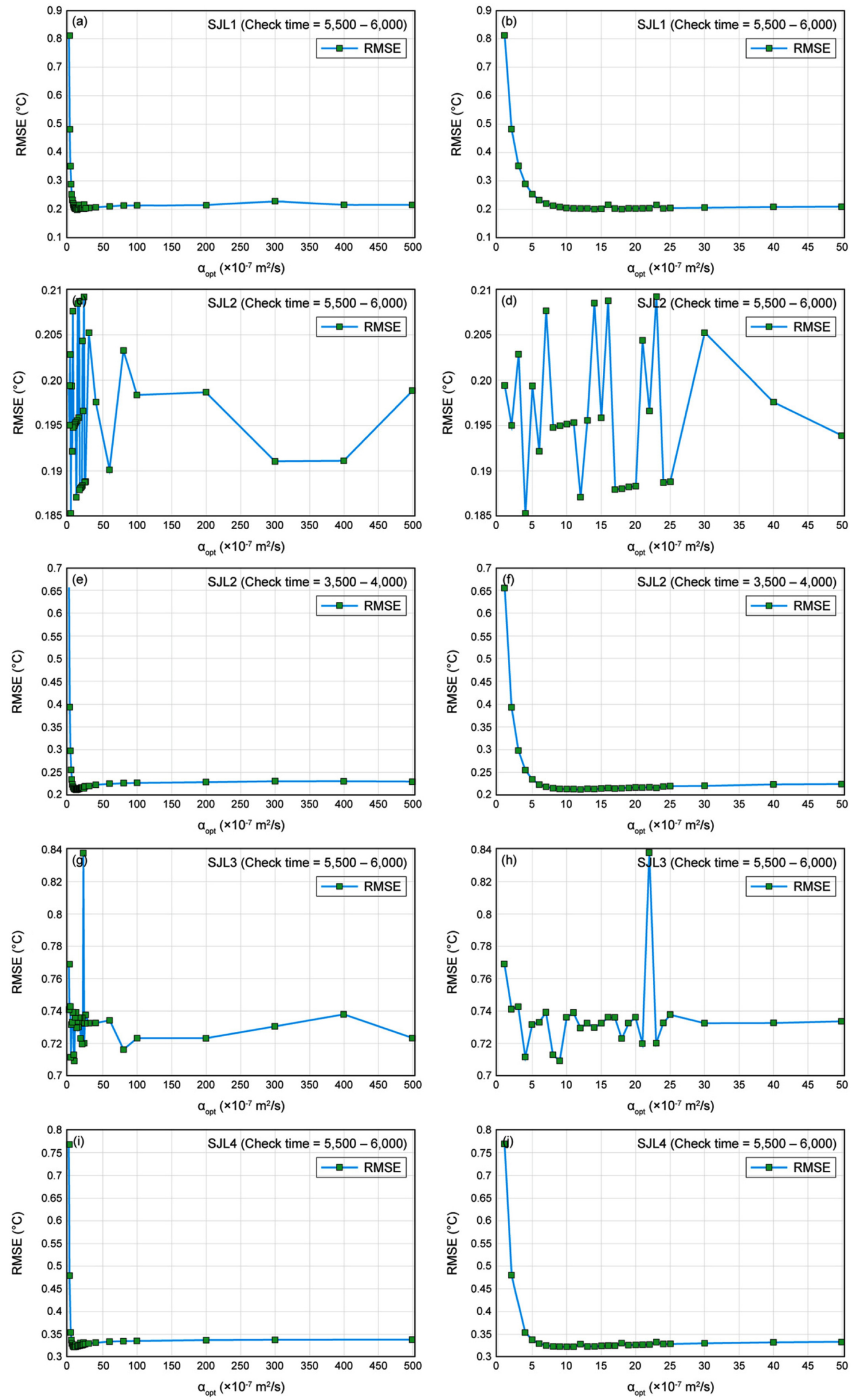

Figure 3. RMS error between the monitoring points. 

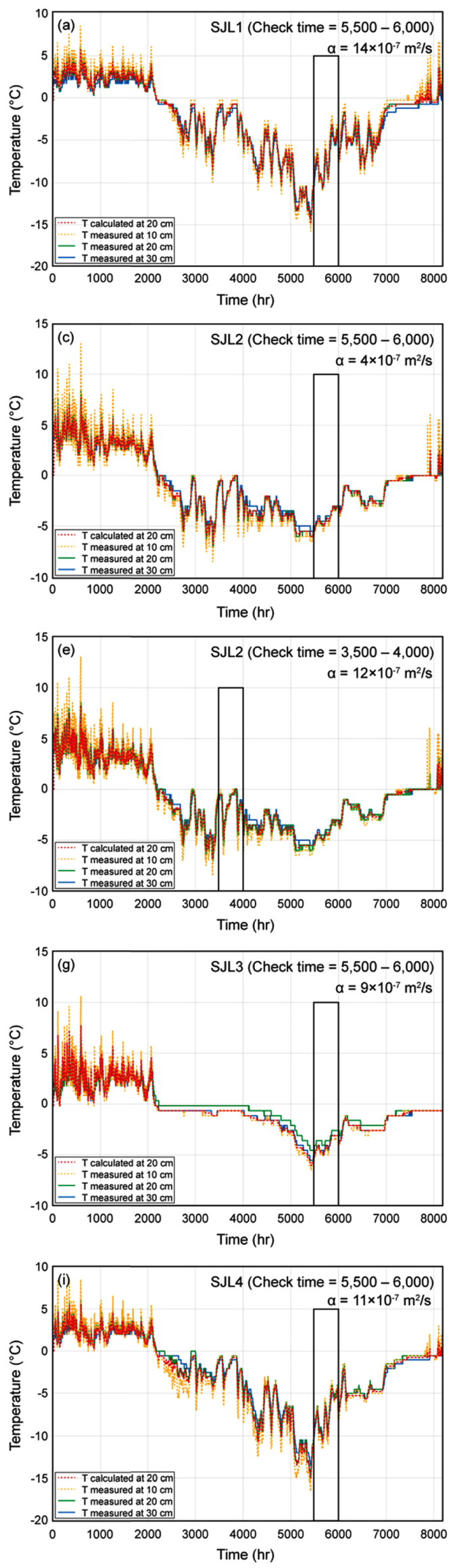
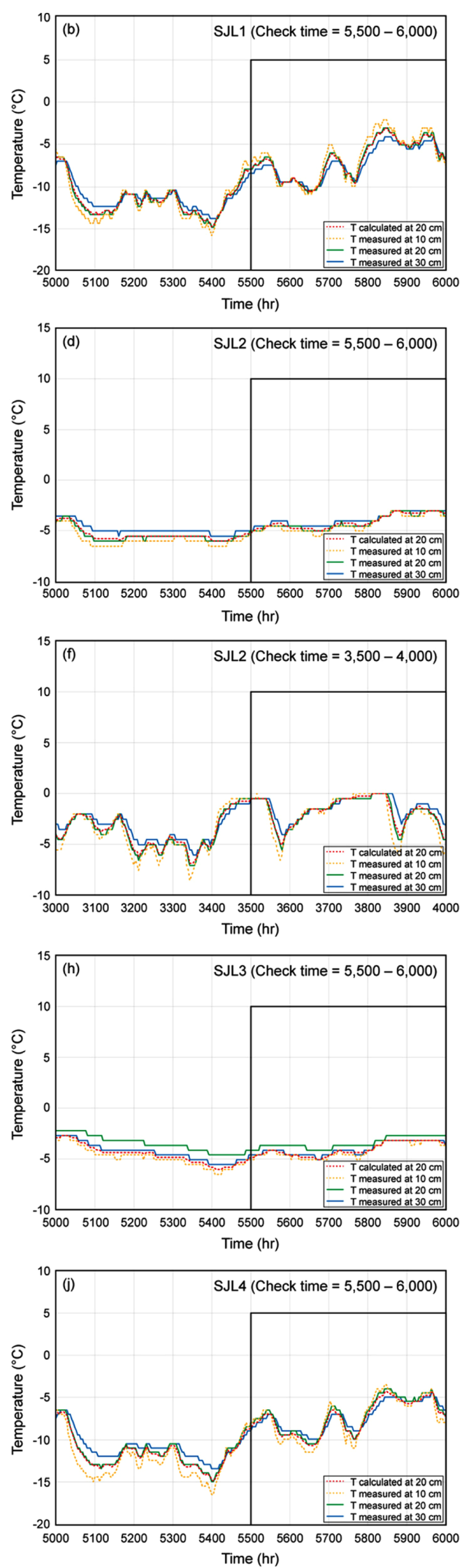

Figure 4. Time series of FEM at points showing a time window for optimum thermal diffusivity; figures on the right are zoomed-in windows of those on the left. 
cessful to give a satisfactory result of RMS errors. Therefore, we tried to set another time range for RMS error calculation for SJL2 and SJL3. For SJL2 was possible to find RMS error time range for RMS error calculation, which was between 3,500 and 4,000 h. Despite these efforts, SJL3 could not find satisfactory time range for RMS error calculation (Fig. 3).

The FEM includes the conduction mode of heat transfer and should be applied to the soil regions having temperatures lower than $0^{\circ} \mathrm{C}$. Fig. 4 also represents the conduction results at temperatures higher than $0^{\circ} \mathrm{C}$; these include temperatures calculated at depths of $0.1,0.2$ and $0.3 \mathrm{~m}$, measured at $4-\mathrm{h}$ time intervals over $6,000 \mathrm{~h}$ using the FEM. This section evaluates the calculated distributions of these temperatures that were measured at the King Sejong Station in Antarctica (see Fig. 2). To investigate quantitatively the effects of the time interval and monitoring depth on thermal diffusivity, numerical FEM experiments were performed for the temperatures measured at King Sejong Station.

Thermal diffusivity values of $14 \times 10^{-7} \mathrm{~m}^{2} / \mathrm{s}$ in SJL1, $12 \times 10^{-7} \mathrm{~m}^{2} / \mathrm{s}$ in SJL2 and $11 \times 10^{-7} \mathrm{~m}^{2} / \mathrm{s}$ in SJL4 were obtained through time series obtained from the application of finite element analysis to the measured $0.1,0.2$ and $0.3 \mathrm{~m}$ soil depths, respectively (Table 1 ). It is consistent with previous reports (Kim et al., 2018). The diffusivity of SJL2 was recalculated with a time window change in order to obtain the optimum thermal diffusivity. The best-fit thermal diffusivity was determined by minimizing the RMS error between the monitored the SJL2 point time series data, for a period between 3,500 and 4,000 h followed by 5,500 and 6,000 h (Fig. 4). However, the temperature time series data at point SJL3 demonstrated problems in estimating thermal diffusivity despite changes in the time window.

\section{Conclusions}

Because heat transfer in both soil and rock is mainly caused by conduction, estimating thermal diffusivity in Antarctica is a necessity in order to cope with climate change. This study estimates thermal diffusivity using FEM analysis of the soil in the King Sejong station, Antarctica. The conclusions drawn from this study are as follows:

Thermal diffusivity in the study area was shown to be in the range $11 \times 10^{-7}$ to $14 \times 10^{-7} \mathrm{~m}^{2} / \mathrm{s}$. The time range for RMS error calculations of the monitoring points SJL1 and SJL4 was 5,500 to $6,000 \mathrm{~h}$; in contrast, the SJL2 and SJL3 points did not demonstrate adequate thermal diffusivity results using the same time range for this calculation. The best-fit thermal diffusivity for the SJL2 point was determined by minimizing the RMS error between the monitored time series data for a period between 3,500 and 4,000 h. The distribution of thermal diffusivity values represented by both negative and positive reflects the drop and rise of the temperature, respectively.

For the SJL3 point, this tendency was not present and it was, therefore, impossible to estimate thermal diffusivity using temperature data. Heat transfer by convection played a major role in the polar activity layer in the SJL1, SJL2 and SJL4 locations. However, as the SJL3 point demonstrated problems in estimating thermal diffusivity using only temperature data, the phase change of environmental factors such as pore water, atmospheric temperature and snow cover should be considered in addition to heat conduction.

\section{Acknowledgements}

This research was financially supported by the Korea Polar Research Institute (KOPRI) Project (PE19200) and Basic Science Research Program through the National Research Foundation of Korea (NRF) funded by the Ministry of Education (No.2019R1A6A1A03033167). The authors give special thanks to Mr. Chang-Seong Kim for his help in preparation for some figures.

\section{References}

Bathe, K., 1996, Finite element procedures, $2^{\text {nd }}$ edition: Prentice Hall, Upper Saddle River, NJ.

Bockheim, J.G., Campbell, I.B., and McLeod, M., 2007, Permafrost distribution and active-layer depths in the McMurdo Dry Valleys, Antarctica. Permafrost and Periglacial Processes, v. 18, pp. 217-227.

Bockheim, J., Vieira, G., Ramos, M., López-Martínez, J., Serrano, E., Guglielmin, M., Wilhelm, K., and Nieuwendam, A., 2013, Climate warming and permafrost dynamics in the Antarctic peninsula region. Global and Planetary Change, v. 100, pp. 215-223.

Boike, J., Roth, K., and Overduin, P.P., 1998, Thermal and hydrologic dynamics of the active layer at a continuous permafrost site (Taymyr peninsula, Siberia). Water Resources Research, v. 34, pp. 355-363.

Boike, J., Hagedorn, B., and Roth, K., 2008, Heat and water transfer processes in permafrost affected soils: a review of field and modeling based studies for the Arctic and Antarctic. Proceedings International Conference on Permafrost, 2008, Institute of Northern Engineering, v. 1, p. $149-154$

Carslaw, H.S., and Jeager, J.C., 1986, Conduction of Heat in Solids ( $2^{\text {nd }}$ edition). Oxford University Press, England, 520 p.

Chang, S.K., Lee, J.I., Choe, M.Y., and Hur, S.D., 2003, Geology around the King Sejong station, King George Island off the Antarctic peninsula. Journal of the Geological Society of Korea, v. 39, pp. 271-286.

Chun, H.Y., and Chang, S.K., 1991, Study on the gymnospermous fossil woods from the King George Island. Korean Journal of Polar Research, v. 2, pp. 179-185.

Cui, M., Gao, X., and Zhang, J., 2012, A new approach for the estimation of temperature-dependent thermal properties by solving transient inverse heat conduction problems. International Journal of Thermal Sciences, v. 58, pp. 113-119.

Ebel, B.A., Koch, J.C., and Walvoord, M.A., 2019, Soil physical, hydraulic, and thermal properties in Interior Alaska, USA: implications for hydrologic response to thawing permafrost conditions. Water Resources Research, v. 55, pp. 4427-4447.

Han, U., Lee, C.K., Nam, S.H., Lee, B.Y., and Kim, Y., 2005, Thermal dynamics of active layer at the Dasan station, Svalbard. Journal of the Geological Society of Korea, v. 41, pp. 91-100.

Han, U., Lee, C.K., Jeong, S.H., Lee, B.Y., and Nam, S.H., 2006, The studies on the temperature and thermal properties of the active layer soil at the Sejong Station, Antarctica. Journal of the Geological Society of Korea, v. 4 , pp. $577-586$.

Hinkel, K.M., 1997, Estimating seasonal values of thermal diffusivity in thawed and frozen soils using temperature time series. Cold Regions Science and Technology, v. 26, pp. 1-15.

Ikard, S.J., Gooseff, M.N., Barrett, J.E., and Takacs-Vesbach, C., 2009, Thermal characterisation of active layer across a soil moisture gradient in the McMurdo Dry Valleys, Antarctica. Permafrost and Periglacial Processes, v. 20, pp. 27-39.

Jeon, W.H., Lee, J.Y., Lim, H.S., and Yoon, H.I., 2016, Comparison of thermal characteristics of soil in austral summer and winter at King Sejong station, King George Island, Antarctica. Journal of the Geolog- 
ical Society of Korea, v. 52, pp. 901-915.

John, B.S., and Sugden, D.E., 1971, Raised marine features and phases of glaciation in the south Shetland Islands. British Antarctic Survey Bulletin, v. 24, pp. 45-111.

Kim, H., Lee, K.K., and Lee, J.Y., 2018, Comparison of Carslaw and Jaeger method and finite element method to estimate temperature of soil in Antarctica. Episodes, v. 41, pp. 1-8.

Koo, M.H., Kim, Y., Suh, M.C., and Suh, M. S., 2003, Estimating thermal diffusivity of soils in Korea using temperature time series data. Journal of the Geological Society of Korea, v. 39, pp. 301-317.

Koo, M.H., and Song, Y., 2008, Estimating apparent thermal diffusivity using temperature time series: a comparison of temperature data measured in KMA boreholes and NGMN wells. Geosciences Journal, v. 12, pp. 255-264.

Koven, C.D., Riley, W.J., and Stern, A., 2013, Analysis of permafrost thermal dynamics and response to climate change in the CMIP5 Earth system models. Journal of Climate, v. 26, pp. 1877-1900.

Lee, J.Y., Lim, H., Yoon, H., and Park, Y., 2013, Stream water and groundwater interaction revealed by temperature monitoring in agricultural areas. Water, v. 5, pp. 1677-1698.

Lee, J.Y., Lim, H.S., and Yoon, H.I., 2016, Thermal characteristics of soil and water during summer at King Sejong station, King George Island, Antarctica. Geosciences Journal, v. 20, pp. 503-516.

Lee, Y.I., Choi, T., and Lim, H.S., 2019, Petrological and geochemical compositions of beach sands of the Barton and Weaver peninsulas of King George Island, West Antarctica: implications for provenance and depositional history. Episodes, v. 42, pp. 149-164.

López-Martínez, J., Serrano, E., and Lee, J. I., 2002, Geomorphological map of Barton and Weaver peninsulas, King George Island, Antarctica (1:10,000). Polar Science Laboratory, Korea Ocean Research and Development Institute, Seoul.

Marchenko, S., Romanovsky, V., and Tipenko, G., 2008, Numerical modeling of spatial permafrost dynamics in Alaska. Proceedings International Conference on Permafrost, 2008, Institute of Northern Engineering, v. 2, p. 1125-1130

Nabelek, P.I., Hofmeister, A.M., and Whittington, A.G., 2012, The influence of temperature-dependent thermal diffusivity on the conductive cooling rates of plutons and temperature-time paths in contact aureoles. Earth and Planetary Science Letters, v. 317, pp. 157-164.

Pradhan, N.R., Downer, C.W., and Marchenko, S., 2019, Catchment hydrological modeling with soil thermal dynamics during seasonal freeze-thaw cycles. Water, v. 11. doi:10.3390/w11010116

Pringle, D.J., Dickinson, W.W., Trodahl, H.J., and Pyne, A.R., 2003, Depth and seasonal variations in the thermal properties of Antarctic dry valley permafrost from temperature time series analysis. Journal of Geophysical Research: Solid Earth, v. 108. doi:10.1029/2002JB002364.

Pringle, D.J., Eicken, H., Trodahl, H.J., and Backstrom, L.G.E., 2007, Thermal conductivity of landfast Antarctic and Arctic sea ice. Journal of Geophysical Research: Oceans, v. 112. doi:10.1029/2006JC003641.

Romanovsky, V.E., Sergueev, D.O., and Osterkamp, T.E., 2003, Temporal variations in the active layer and near-surface permafrost temperatures at the long-term observatories in northern Alaska. Proceedings International Conference on Permafrost, 2003, Institute of Northern Engineering, v. 1, p. 989-994.

Roth, K., and Boike, J., 2001, Quantifying the thermal dynamics of a permafrost site near Ny-Ålesund, Svalbard. Water Resources Research, v. 37, pp. 2901-2914

Smellie, J.L., Pankhurst, R., Thomson, M.R.A., and Davies, R.E.S., 1984, The geology of the south Shetland Islands: VI. Stratigraphy, geochemistry and evolution. British Antarctic Survey, Cambridge, $85 \mathrm{p}$.

Vieira, G., Bockheim, J., Guglielmin, M., Balks, M., Abramov, A.A., Boelhouwers, J., Cannone, N., Ganzert, L., Gilichinsky, D.A., Goryachkin, S., López-Martínez, J., Meiklejohn, I., Raffi, R., Ramos, M., Schaefer, C., Serrano, E., Simas, F., Sletten, R., and Wagner, D., 2010, Thermal state of permafrost and active-layer monitoring in the Antarctic: advances during the international polar year 2007-2009. Permafrost and Periglacial Processes, v. 21, pp. 182-197.

Wang, Q., Yang, Q., Guo, H., Xiao, X., Jin, H., Li, L., Zhang, T., and Wu, Q., 2019, Hydrothermal variations in soils resulting from the freezing and thawing processes in the active layer of an alpine grassland in the Qilian Mountains, northeastern Tibetan Plateau. Theoretical and Applied Climatology, v. 136, pp. 929-941.

Weismüller, J., Wollschläger, U., Boike, J., Pan, X., Yu, Q., and Roth, K., 2011, Modeling the thermal dynamics of the active layer at two contrasting permafrost sites on Svalbard and on the Tibetan Plateau. The Cryosphere, v. 5, pp. 741-757.

Wu, Q., and Zhang, T., 2010, Changes in active layer thickness over the Qinghai-Tibetan Plateau from 1995 to 2007. Journal of Geophysical Research: Atmospheres, v. 115. doi:10.1029/2009JD012974.

Yoo, C.M., Choe, M.Y., Jo, H.R., Kim, Y.D., and Kim, K.H., 2001, Volcaniclastic sedimentation of the Sejong formation (late Paleocene-Eocene), Barton peninsula, King George Island, Antarctica. Ocean and Polar Research, v. 23, pp. 97-107.

Yoshikawa, K., and Hinzman, L.D., 2003, Shrinking thermokarst ponds and groundwater dynamics in discontinuous permafrost near Council, Alaska. Permafrost and Periglacial Processes, v. 14, pp. 151-160.

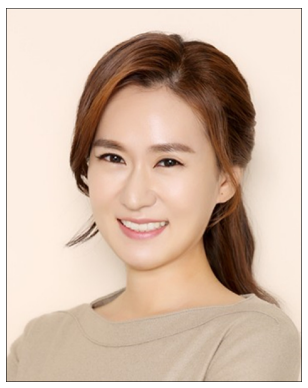

Heejung Kim is a Research Professor of hydrogeology in the Research Institute for Earth Resources in Kangwon National University, Korea. She received her Ph.D. degree from School of Earth and Environmental Sciences, Seoul National University, Korea in 2015. She was awarded the 2018 young geologist from the Geological Society of Korea. Her research interests include groundwater-stream water interaction, karst hydrology, and microbial diversity in groundwater.

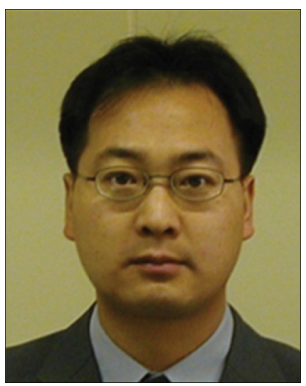

Jin-Yong Lee is a Full Professor at Kangwon National University. He has published over 220 research papers in international and Korean journals. He was awarded the Young Geologist Award, the Commendation Award from Environment Minister, Academic Award and Best Paper Award from The Geological Society of Korea, Academic Award from Korea Federation of Water Science and Engineering Societies, Academic and Contribution Awards from the Korean Society of Soil and Groundwater Environment, Commendation Award from Minister of Science and ICT, and Order of Science and Technological Merit from President of Republic of Korea. He has served as the Editor-in-Chief for the Journal of the Geological Society of Korea, as the Associate Editor for Geoscience Journal, and as the Editor-in-Chief for Episodes, Journal of International Geoscience.

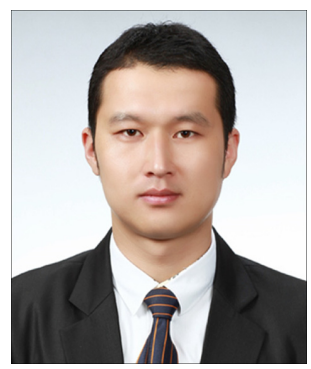

Kitae Kim is a Senior Research Scientist at Korea Polar Research Institute (KOPRI) and Associated Professor at University of Science and Technology (UST), Korea. He received his Ph.D. from Pohang University of Science and Technology (POSTECH), Korea. He was awarded the Prime Minister Award from Korean Government (2016), Young Scientist Award from Korean Chemical Society (2017), and Best Lecturer Award form UST (2018). His main research focuses on the intrinsic geochemical reactions in ice phase and its environmental implications. 